\title{
How Abuse-Resistant are the Abuse-Deterrent Medications
}

\author{
David J . Mastropietro and Hossein Omidian* \\ Department of Pharmaceutical Sciences, College of Pharmacy, Nova Southeastern University, USA
}

\begin{abstract}
Received: October 30, 2013; Accepted: December 10, 2013; Published: December 15, 2013
"Corresponding author: Hossein Omidian, Department of Pharmaceutical Sciences, College of Pharmacy, Nova Southeastern University, 3200 South University Drive, Fort Lauderdale, FL, 33328, USA, Tel: 954262 1334; E-mail: omidian@nova.edu
\end{abstract}

Keywords: Abuse deterrent; Abuse liability; Formulation; Tamper resistant; opioids

\section{Editorial}

The major goal of abuse-deterrent formulations is to help reduce and prevent harm associated with the misuse and abuse of prescription medications. Currently, only a handful of prescription opioid medications have utilized these technologies in both immediate and extended-release formulations. Additionally, an over-the counter cold medication (Zephrex- ${ }^{\circledR}$ ) has entered the market using an abuse-deterrent formulation that inhibits extraction of pseudoephedrine to prohibit illicit methamphetamine production. As these novel formulations move into clinical practice, ways of testing and proving their level of abuse resistance both in-vitro and in the real world has been a topic of great interest.

In pharmacy, we see plenty of examples where the word "resistant" is used to signify when something is not affected by something else or is prevented from happening. Such examples include light-resistant packaging, antibiotic-resistant bacteria, tamper-resistant prescription pads, and child-resistant closures. Over time, we often start to associate the word "resistant" with "proof" and assume a higher level of safety than what is really implied. Abuse-deterrent formulations are no different in that they are meant to deter someone from abusing a prescription product by common methods of abuse. These products do not come with a guarantee of being abuse-proof, they simply add resistance to abuse by making it more time consuming or require special handling and multiple steps to acquire the drug for alternate routes of administration or faster absorption. This is similar to child-resistant closures used on bottles. Such closure systems are only required to keep $20 \%$ or less of children from gaining access to a bottle within 10 minutes. As with children, this means that if given ample time, and with continued persistence, an abuser can become successful at gaining access to potentially harmful drugs in tamper-resistant formulations.

An ideal abuse-deterrent formulation would need to be resistant to all types of tampering and misuse to be considered abuse-proof. Since this is not practical, the more abuse methods the product is resistant to, the more ideal it will become to being abuse-proof. A product formulation should therefore focus on being resistant to the most likely methods of abuse. A list of common tampering and abuse methods are listed in the following table. This table also describes some ideal properties a formulation may possess to impart resistance to each of these methods. It should be noted that each individual drug will have its preferred methods of abuse in the general population. For example, intravenous injection may be rarely seen with one drug but be the most preferred route for another. This is a major factor that should be considered when developing or choosing an abusedeterrent formulation. It is also worth noting that the element of time plays a crucial role in deterring abuse. The longer it takes to render a product into an abusable state, the more deterrent it becomes and likely assumed to have a lower potential for abuse. The standard product that can be used for comparison should be a traditional dosage form of the same drug strength or a drug of equivalent dose and likelihood of abuse

Abuse-deterrent formulations are just one way to help curb improper methods of manipulation and abuse of prescription drugs having high addiction and abuse potential. These formulations can act as resistant barrier to both intentional and inadvertent methods of tampering and misuse. The FDA has mentioned its concern about the growing rise of prescription drug abuse, and has strongly supported the efforts of abuse-deterrent formulations. It has evengone as far as stopping approval of generic versions of original formulations of Oxycontin ${ }^{\circledR}$ (oxycodone hydrochloride controlled release) that do not have properties comparable to the newer abuse-deterrent formulation. It was therefore surprising to most its recent (October 2013) approval of Zohydro ${ }^{\mathrm{TM}}$ ER, a first of its kind extended release single entity hydrocodone product that has no abuse deterrence built into the capsule formulation of this highly abused opioid. The increased morbidity and mortality from prescription opioid formulations, particularly those having extended-release formulations, has shown to be a great risk to the public when abused improperly. To improve the protection of public health, it would be advisable to mandate that all addictive opioids, and other drugs of high abuse, use drug delivery platforms having as close to an ideal abuse-resistant formulation as is currently available. We remain hopefully that the FDA will stay committed to strict product labeling and obligate pharmaceutical manufacturers to develop 


\begin{tabular}{|c|c|}
\hline Method of Abuse & Ideal Formulation Properties \\
\hline crush/grind/grate & $\begin{array}{l}\text { high mechanical strength or viscoelastic properties } \\
\text { maintain intended rate and extent of drug absorption upon reduction in particle size } \\
\text { maintain properties over large range of temperatures }\end{array}$ \\
\hline mastication & $\begin{array}{l}\text { resistance to fracturing and particle size reduction in the presence of saliva } \\
\text { have a mechanical force higher than human bite-force }\end{array}$ \\
\hline intravenous injection & $\begin{array}{l}\text { high syringeability and injectability forces } \\
\text { resistant to filtration } \\
\text { resistant to particle size reduction and rapid dissolution }\end{array}$ \\
\hline nasal insufflation & $\begin{array}{l}\text { poor flow properties of crushed product } \\
\text { resistant to particle size reduction } \\
\text { high product mass needed for inhalation to achieve euphoric effects } \\
\text { use of aversive agent to cause nasal irritation and discomfort }\end{array}$ \\
\hline inhalation by vaporization & $\begin{array}{l}\text { low product char temperature } \\
\text { lower vapor pressure of active ingredient }\end{array}$ \\
\hline ethanol co-ingestion & $\begin{array}{l}\text { non-accelerated dissolution of drug in ethanol } \\
\text { devoid of ethanol sensitive coatings and excipients }\end{array}$ \\
\hline multiple oral dose administration & $\begin{array}{l}\text { aversive agent that is effective at low doses } \\
\text { drug absorption is not dissolution dependent } \\
\text { presence of multiple doses inactivate drug release and dissolution }\end{array}$ \\
\hline heating/microwaving & $\begin{array}{l}\text { excipients remain stable at high temperatures (e.g. high Tg polymers) } \\
\text { active ingredient unstable at prolonged high temperatures } \\
\text { product inactivates under electromagnetic radiation or high thermal events }\end{array}$ \\
\hline freezing & $\begin{array}{l}\text { resistant to particle size reduction when placed into a freezer, dry-ice, or liquid nitrogen } \\
\text { excipients remain stable at low temperatures (e.g. low Tg polymers) }\end{array}$ \\
\hline solvent extraction & $\begin{array}{l}\text { resistance to solvents of various } \mathrm{pH} \text {, ionic strength, and temperature } \\
\text { multistep extraction processes }\end{array}$ \\
\hline
\end{tabular}

abuse-deterrent products with reduced abuse potential for high risk medications.

\section{References}

1. Mastropietro, D. J., \& Omidian, H. (2013). Current approaches in tamper-resistant and abusedeterrent formulations. Drug Development and Industrial Pharmacy, 39(5), 611-24.

2. Mastropietro, D. J., \& Omidian, H. (2013). Commercial abuse-deterrent dosage forms: clinical status. Journal of Developing Drugs, 2(1), 103.

3. Omidian H., \& Mastropietro, D. J. (2013). Fighting a New Drug
Epidemic. Journal of Developing Drugs, 2(1).

4. U.S. National Archives and Records Administration.

5. http://zephrex-d.com/

6. http://www.fda.gov/downloads/Drugs/GuidanceComplianceRegulatoryInformation/Guidances/UCM334743.pdf

7. http://www.fda.gov/drugs/drugsafety/informationbydrugclass/ ucm369273.htm 